\title{
Delivering contraceptive vaginal rings-Task sharing in the delivery of family planning programs: Experiences from Senegal
}

\author{
Babacar Mane \\ Population Council \\ Nafissatou Diop \\ Population Council \\ Saumya RamaRao \\ Population Council
}

Follow this and additional works at: https://knowledgecommons.popcouncil.org/departments_sbsr-rh

Part of the Demography, Population, and Ecology Commons, Family, Life Course, and Society Commons, International Public Health Commons, and the Women's Health Commons How does access to this work benefit you? Let us know!

\section{Recommended Citation}

Mane, Babacar, Nafissatou Diop, and Saumya RamaRao. 2015. "Delivering contraceptive vaginal rings-Task sharing in the delivery of family planning programs: Experiences from Senegal." Dakar: Population Council. 


\section{DELIVERING CONTRACEPTIVE VAGINAL RINGS}

Task sharing in the delivery of family planning services: Experiences from Senegal

Babacar Mané Nafissatou Diop Saumya RamaRao 


\section{POPULATION}

COUNCIL

Ideas. Evidence. Impact.

The Population Council confronts critical health and development issues-from stopping the spread of HIV to improving reproductive health and ensuring that young people lead full and productive lives. Through biomedical, social science, and public health research in 50 countries, we work with our partners to deliver solutions that lead to more effective policies, programs, and technologies that improve lives around the world. Established in 1952 and headquartered in New York, the Council is a nongovernmental, nonprofit organization governed by an international board of trustees.

Population Council

Sacré Cœur 3. Lot 85. BP 21027

Dakar, Senegal

Tel: (221) 338595300

Fax: (221) 338241998

www.popcouncil.org

Suggested citation: Mané B., Diop N., and RamaRao S. 2014. Delivering Contraceptive Vaginal Rings-Tasking Sharing in the Delivery of Family Planning Programs: Experiences from Senegal. Dakar: Population Council.

(C) 2015 The Population Council, Inc. 


\section{Table of Contents}

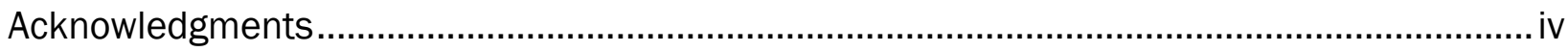

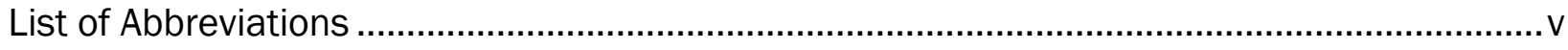

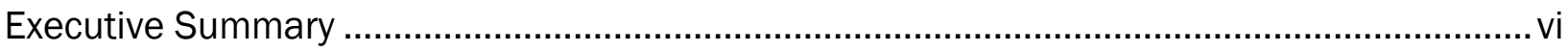

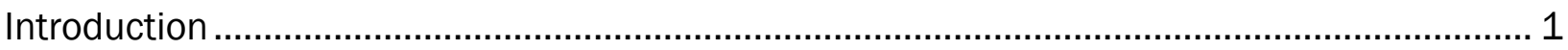

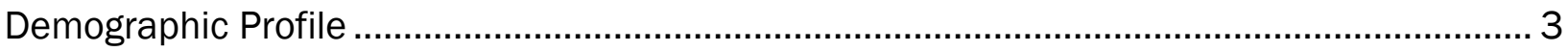

Childbearing and Contraceptive Behavior..................................................................... 3

Distribution of Facilities and Human Resources for Health.............................................. 7

Considerations for Introducing Contraceptive Vaginal Rings .............................................. 10

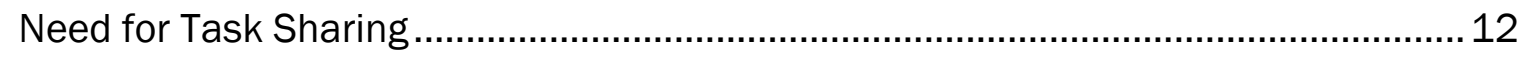

Task Sharing Initiatives .......................................................................... 12

Current Task Sharing Policy in Senegal........................................................... 13

Successful Task Sharing Activities ................................................................. 15

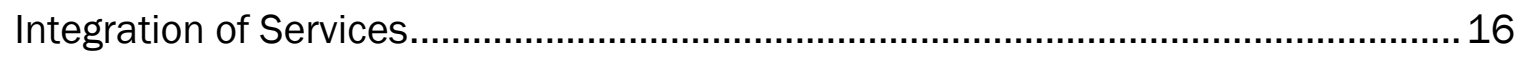

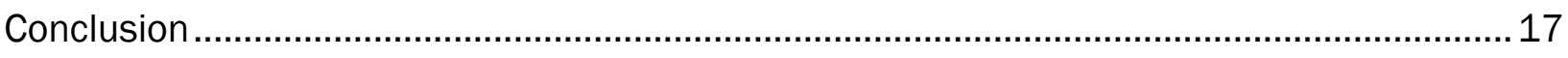

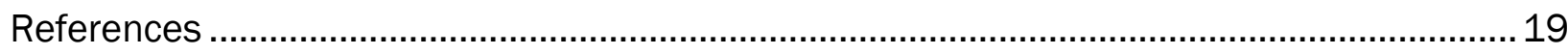




\section{Acknowledgments}

The authors thank all the partners for their availability to share their experiences. Special thanks to the Directorate of Reproductive Health and Child Survival (DSRSE) of the Ministry of Health and Social Affairs, CEFOREP, PATH, CHILDFUND and FHI360 for making available key documentation and providing in-depth answers to our queries. 


\section{List of Abbreviations}

\begin{tabular}{|c|c|}
\hline ANC & Antenatal Care \\
\hline ANSD & Agence Nationale de la Statistique et de la Démographie \\
\hline ASC & Community health agents \\
\hline BAD & African Development Bank \\
\hline BMFG & Bill and Melinda Gates Foundation \\
\hline CBD & Community Based Distribution \\
\hline CEFOREP & Centre de Formation et de Recherche en Santé de la Reproduction \\
\hline CGO & Clinic of Gynecology and Obstetrics \\
\hline $\mathrm{CHW}$ & Community Health Workers \\
\hline CPR & Contraceptive Prevalence Rate \\
\hline CVR & Contraceptive Vaginal Ring \\
\hline DHS & Demographic and Health Survey \\
\hline DMPA-IM & Depot medroxyprogesterone acetate \\
\hline DPP & Declaration of Population Policy \\
\hline FP & Family Planning \\
\hline FP2020 & Family Planning 2020 \\
\hline IM & Intra Muscular \\
\hline IUD & Intra Uterine Device \\
\hline LAM & Lactational Amenorrhea Method \\
\hline MICS & Multiple Indicator Cluster Survey \\
\hline $\mathrm{MNCH}$ & Maternal, Neonatal and Child Health \\
\hline $\mathrm{MNH}$ & Maternal and Neonatal Health \\
\hline $\mathrm{MoH}$ & Ministry of Health \\
\hline NES/EE CVR & Nestorone ${ }^{\circledR} /$ Ethinyl-Estradiol contraceptive vaginal ring \\
\hline NGO & Non-governmental Organization \\
\hline ORS & Oral Rehydration Solution \\
\hline PCVR & Progesterone contraceptive vaginal ring \\
\hline PNDS & Plan National de Développement Sanitaire \\
\hline $\mathrm{RH}$ & Reproductive Health \\
\hline SDP & Service Delivery Point \\
\hline SSA & Sub-Saharan Africa \\
\hline TFR & Total Fertility Rate \\
\hline USAID & United States Agency for International Development \\
\hline WHO & World Health Organization \\
\hline
\end{tabular}




\section{Executive Summary}

With support from the Bill \& Melinda Gates Foundation (BMGF) and United States Agency for International Agency (USAID), the Population Council is conducting various pre-introductory activities to facilitate the introduction of vaginal rings in sub-Saharan Africa (SSA). The first vaginal ring to be introduced will be the Progesterone Contraceptive Vaginal Ring (PCVR) since it is relevant in contexts where women practice prolonged lactation. It will also address the high unmet need for family planning (FP), especially for postpartum women. Under a cooperative agreement with USAID, in collaboration with WomanCare Global (WCG), the Council aims to expand the availability and affordability of vaginal rings including the PCVR in 3 developing countries, specifically Kenya, Nigeria and Senegal. To reach this goal, the Population Council initiated documentation and research to generate evidence for implementing appropriate service delivery models for the PCVR to address major challenges in the provision of FP services in each country. One of these challenges is to address the lack of skilled providers which constitutes a real limit on access to FP services. To design plans for involving mid- and lower-level health workers in PCVR provision, the project conducted a review of task sharing experiences in the three countries where task sharing of critical $\mathrm{MNCH}$ service delivery functions to various degrees and with varying results.

\section{KEY OBJECTIVES}

- Assess the policy support for task sharing, the extent to which it has been implemented (or not), and lessons from Senegal.

- Assess the interest exhibited and opportunities provided to further develop the strategy for involving mid- and lower-level providers and for subsequently designing an intervention.

\section{RESULTS}

\section{Availability of human resources}

Analysis of human resources availability indicates an unequal distribution of the health care workforce within the country. In 2011, Senegal counted 1803 physicians; the majority of them were based in the regions of Dakar and Thiès, $71 \%$ and $8 \%$ respectively. The need for physicians in 2011 was estimated at 413 for reaching the Ministry of Health $(\mathrm{MoH})$ norms. While the ratio was at 2,305 habitants per physician in Dakar, in Sedhiou region this indicator was at 88,540 habitants and at 63,637 habitants in Kaffrine region. Considering the category of midwives, in 2011 Senegal counted 1103 midwives. As for physicians, Dakar region concentrated 37\% of this category of providers and big gaps are noted between Dakar and the rest of the country. This situation calls for an implementation of alternative strategies that could improve access to health services. Task shifting/sharing could be an effective strategy that can contribute to adequately address multiple barriers to access. 


\section{Policy environment}

Both the "Plan National de Développement Sanitaire et Social. 2009-2011" and National Family Planning Action Plan for 2012-2015 demonstrated willingness by the authorities to reinforce access to FP services. The objective is to increase the current Contraceptive Prevalence Rate (CPR) from $12 \%$ to $27 \%$ by 2015 and to $45 \%$ by 2020 . The main strategic approach to these plans includes establishing provisions for task shifting, demedicalization of FP services, and implementation of community health interventions.

\section{Task Sharing Initiatives in Family Planning (FP) sector}

With the support of the national authorities, various task shifting initiatives were undertaken in the country.

- FP initial counseling by matrons at service delivery levels: This initiative revealed that matrons, when trained, can perform effective FP counseling for women. This experience allows the midwives to focus on more clinical tasks and as a result lighten their workload. The scaling up of this initiative is now effective throughout the country.

- Initial offer of pills by matrons at community level (health huts): matrons showed that they can offer pills in their community in a safe manner. Positive lessons learned from this experience prompted the $\mathrm{MoH}$ to scale up this initiative throughout the country.

- Long-acting method offered by nurses at health post level: Before the intervention, long-acting methods were only available in hospitals and health centers. Evaluation of this initiative indicated that trained nurses can safely offer long acting methods. The initiative contributes to expand FP choice for women living in remote areas and helped to reinforce access to FP services. Nurses expressed great motivation in performing this task.

- DMPA-IM offered by matrons and community health agents: Results from the evaluation showed that matrons and community health agents developed the necessary skills in providing DMPA-IM correctly. Clients and indirect beneficiaries as well as other health workers appreciated this task sharing experience. Ninety-nine percent of clients appreciated the expanded access to FP methods and reported that they intended to get their next injectable at health huts. Introduction of DMPA-IM also contributes to the diversification of methods offered at the health hut level. Matrons and community health workers (CHWs) served around 1,078 FP clients. Among them, 670 chose injectables.

- Administration and acceptability of Depo-subQ Provera 104 TM in Uniject: Findings from the evaluation demonstrated that trained matrons can safely administer DeposubQ in Uniject. No adverse events related to Depo-subQ in Uniject were reported. Clients showed interest in the method and confirmed the potential of Depo-subQ in increasing FP access through community-based distribution. Clients not only found the new method acceptable but also the provision of service by matrons. Following this positive experience, the $\mathrm{MoH}$ signed an official note for scaling up this initiative throughout the country as stated by the National Plan on Best Practices Scaling Up in August 2014. Additional regions such as Dakar, Thies, Fatick and Kaolack will pursue similar activities in 2015. 


\section{Successful Task Sharing Activities}

Evaluation of task sharing experiences in Senegal revealed that, when well trained, CHWs can properly offer a basic package of primary health care services in the community. They are able to provide comprehensive health services and triage health questions and complaints whenever brought to their attention by community members. Moreover, services offered at the community level (health huts) were of acceptable quality and greatly appreciated. A recent evaluation led by USAID on the initial offer of pills confirmed that, when asked their opinion about the quality of the services they received at the time of their visit to the health huts, 95\% of clients expressed their complete satisfaction.

It was also noted that, with the presence of the $\mathrm{CHW}$, a strong demand for family planning services expressed by women in the communities was identified. In fact, presence of these CHWs constitutes an opportunity to increase the demand for FP. Increased demand for FP resulted from a more aware community through the education activities led by CHWs. Moreover, findings from these initiatives noted an increase in the utilization of services. In addition, the presence of $\mathrm{CHWs}$, as reported by a head nurse, has led to a reduction in the caseload at the health post. Head nurses can now focus more on treating serious cases of malaria, diarrhea and respiratory infections. There are also geographic and financial advantages related to the availability of competent services at the level of the health huts. Thus, task sharing has contributed to reducing the long distance of these facilities as transport to a health facility is time-consuming and costly. With task sharing introduction, communities can now have greater access to services at less cost in time and money. Through their educational activities in the community, CHWs showed their ability to address cultural barriers limiting utilization of health services by individuals and families, especially in rural areas. Providers and local management teams confirmed that $\mathrm{CHWs}$ and matrons can systematically observe the norms and protocols.

\section{CONCLUSION}

Positive previous initiatives of task shifting led in country suggest that introduction of the contraceptive vaginal ring could have greater future potential in Senegal. With the launch of its National FP action plan, the national authorities expressed a real commitment to sustain the repositioning of the FP program. Demedicalization of FP services by giving a central role to community actors and the improvement of access to FP services constitutes a central strategy of this action plan. Recent initiatives of task shifting demonstrated that CHWs can perform effective and good quality services in their communities. These experiences contributed to increase access and uptake of FP services. To consolidate these results, the MoH adopted a plan for scaling up all best practices throughout the country. The existing dense network of community health workers such as relais, matrons and Badienu Gox could benefit PCVR introduction and provide an opportunity for addressing the crucial shortage of skilled health workers, particularly in remote rural areas. However, it is important to anticipate similar complications faced by previous initiatives, which include: (1) sustainability; (2) availability of resources; and (3) likely challenges related systems being decentralized. 


\section{Introduction}

Achieving the Family Planning 2020 (FP2020) goal of reaching 120 million new users in the world's poorest countries with voluntary family planning services, information, and supplies requires innovative technologies and creative solutions. The need for effective contraception is especially acute in the 69 poorest countries in Africa, where from 2008 to 2012 the number of women with an unmet need increased from 153 to 162 million.

One important sub-group with a large unmet need for contraception (17\%) is postpartum women (Guttmacher Institute, 2012). In general, less than 25 percent of women use contraception during the first six to twelve months postpartum, and about half of all users abandon their method within six months of adoption. Failure to meet women's contraceptive needs during this critical period has consequences for the health of mothers and their newborns.

Intravaginal contraceptive rings, including the Progesterone Contraceptive Vaginal Ring (PCVR) and Nestorone ${ }^{\circledR} /$ Ethinyl-Estradiol Contraceptive Vaginal Ring (NES/EE CVR), can play a key role in increasing access to contraception for millions of women. Furthermore, since these methods are user-initiated, they will contribute to reinforcing women's autonomy and empowerment.

The PCVR is particularly appropriate in settings where women practice prolonged breastfeeding and have an unmet need for contraceptive protection. Its introduction in Senegal will offer an opportunity to extend contraceptive choices for women in the first year postpartum. Indeed, the methods that are suitable and available to breastfeeding mothers are Lactational Amenorrhea Method (LAM), progesterone-only pills, male and female condoms, and clinical methods such as implants, IUDs, and injections. Clinical methods require a trained health provider along with specialized equipment and supplies at the point of service-both of which are often unavailable at the lower level health facilities (i.e. health centers, health posts and health huts) that women can most easily access, especially in rural areas. Thus, the PCVR will enhance available contraceptive choice, especially in health facilities where only a mid- or lower-level health provider, such as a nurse, midwife, or outreach worker, is present.

The Population Council, with funding from the Bill \& Melinda Gates Foundation (BMFG) and United States Agency for International Development (USAID), is conducting pre-introductory activities to facilitate the availability of contraceptive vaginal rings in sub-Saharan Africa (SSA). The PCVR is the first ring slated for introduction in Senegal, in collaboration with the Ministry of Health and Social Affairs and global partners such as WomanCare Global (WCG).

As part of its pre-introductory activities, the Population Council conducted a landscape analysis of the availability of health workers to document if and how they could have an 
effect on the delivery of contraceptive vaginal rings. In SSA, where there are fewer than 2.3 health professionals per 1,000 people (WHO, 2012), the lack of trained health workers severely limits women's access to family planning services. The Population Council's family of vaginal rings, including the PCVR and NES/EE CVR, offers one solution as the rings require minimum provider-user interaction, can be offered by mid-level health workers (e.g. nurses and midwives) and have the potential for distribution by lower-level (e.g. community health workers) providers. Furthermore, these methods are womaninitiated, easy to dispense, and use. Self-control is also an attractive and important feature of the rings. Furthermore, providers do not require extensive training, particularly clinical training, in order to adequately offer this method. Hence, vaginal rings can be offered by a range of health providers including first-line providers, such as nurses, midwives and pharmacists, as well as by community-based workers after an initial consultation with a health professional.

Task Sharing and Task Shifting are commonly defined as follows:

- Task sharing may refer to higher and lower level workers providing the same service (e.g. both lower and higher level workers provide condoms), or providing different components of the same service (e.g. a lower level worker provides family planning education and referrals to a higher level worker who actually provides contraceptives). Task sharing is implicit in all programs with more than one worker dedicated to the same health area.

- Task shifting involves the redistribution of tasks amongst health workforce teams. Specific tasks are moved from more highly skilled health workers to health workers with fewer qualifications and less formal training. Although the term is often used interchangeably to mean task sharing or role expansion, true task shifting usually occurs in clinical settings. For example, a volunteer provides education and counseling to clients, a task previously performed by a nurse. The nurse is then freed to perform more clinical and administrative tasks.

The recent World Health Organization (WHO) Optimize Maternal, Neonatal and Child Health $(\mathrm{MNH})$ guidance provides recommendations on task sharing and task shifting for safe provision of contraceptives by various cadres of health workers, from lay community workers to mid-level providers. 
Table 1: WHO recommendations: Optimizing health worker roles to improve access to key maternal and newborn health interventions through task shifting.

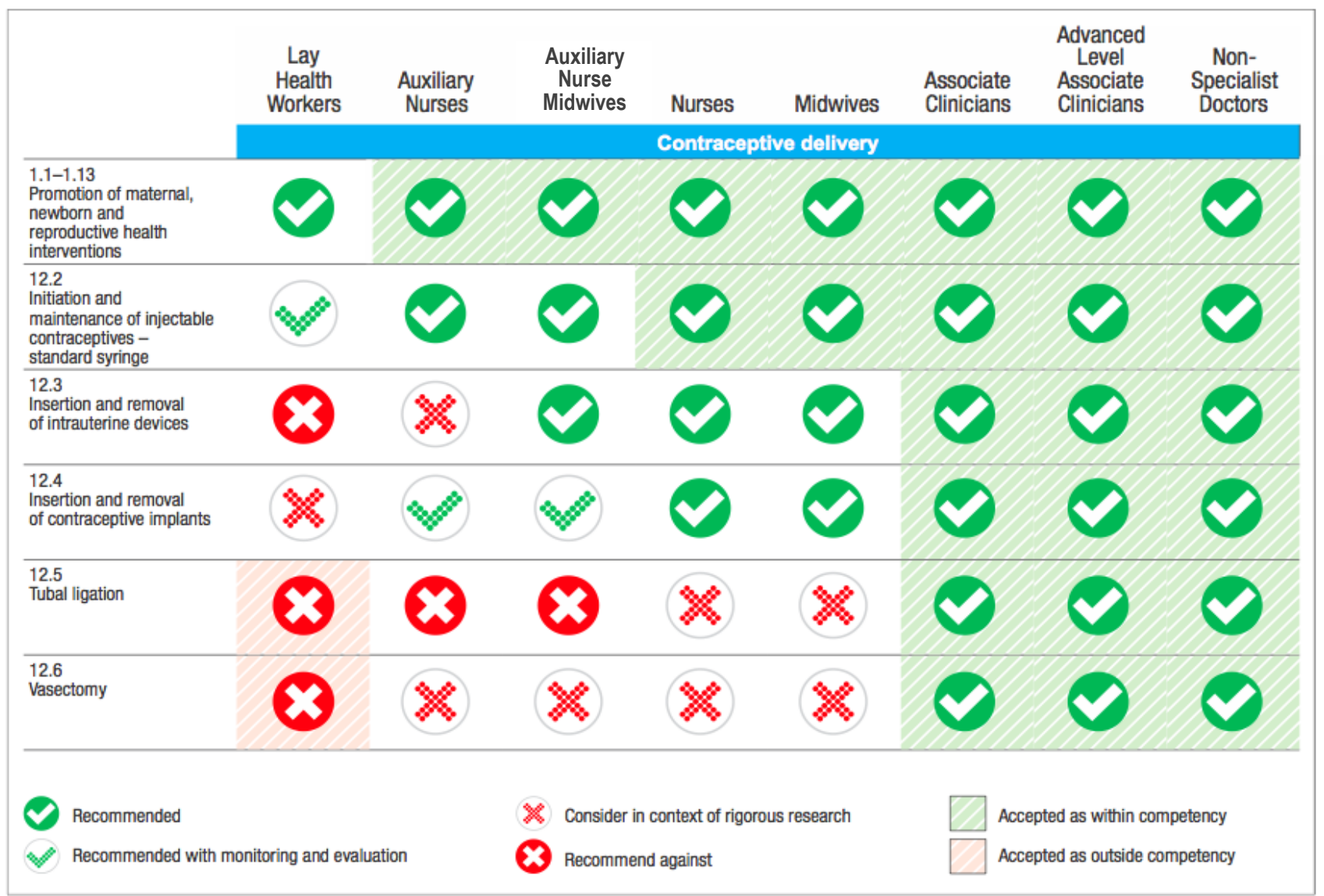

Source: WHO recommendations: Optimizing health worker roles to improve access to key maternal and newborn health interventions through task shifting". Geneva, 2012.

The Population Council conducted a review of past and current task sharing experiences to help develop evidence-informed policies and programs for involving lower- and midlevel health workers in the provision of PCVR in Senegal. The specific objectives of the review were to:

- Assess policies in support of task sharing/task shifting, the extent to which they have been implemented (or not), and lessons learned.

- Assess interest for and opportunities to further develop strategies for involving mid- and lower-level providers and subsequently designing an intervention.

The report begins with a description of the current demographic profile of the country including reproductive and contraceptive patterns, followed by a description of the health care system and task shifting initiatives and ends with implications for introducing contraceptive vaginal rings. 


\section{DEMOGRAPHIC PROFILE}

In 2013, the population of Senegal was estimated at 12.9 million people (ANSD, 2014). This represents a near doubling of the population in 25 years from 6.9 million in 1988 . With a growth rate of approximately $2.5 \%$ per year, Senegal has a young population. In 2013 , approximately $53 \%$ of the population was under the age of 20 . This dynamic can be attributed to long-sustained high fertility rates. In 1986, the Total Fertility Rate (TFR) was at 6.4 children per woman (Figure 1). In 20102011, the TFR dropped to 5.0 children per woman, although there were large differences by urban/rural residence (3.9 children per woman in urban areas compared to 6.0 in rural areas). However, the Continuous DHS revealed a slight increase in TFR estimated at 5.3 children per woman for the period 2012-2013 (ANDS, 2013).

Marriage is almost universal ( $86 \%$ of women age 30 and over were married (ANSD, 2012)). As the 2010-2011 DHS revealed, $16 \%$ of Senegalese girls are married by the age of 15, with $40 \%$ married by the age of 18 . Additionally, $35 \%$ of women overall are involved in polygamous unions, although this is more common in rural areas. School enrollment rates are low, especially for girls. Nearly $60 \%$ of girls and $37 \%$ of boys had no formal education. Furthermore, only $3 \%$ of DHS female respondents and $6 \%$ of male respondents had completed secondary education or higher. Overall, $38 \%$ of all women were literate compared to $60 \%$ of males (ANSD 2012).

FIGURE 1: TOTAL FERTILITY RATE

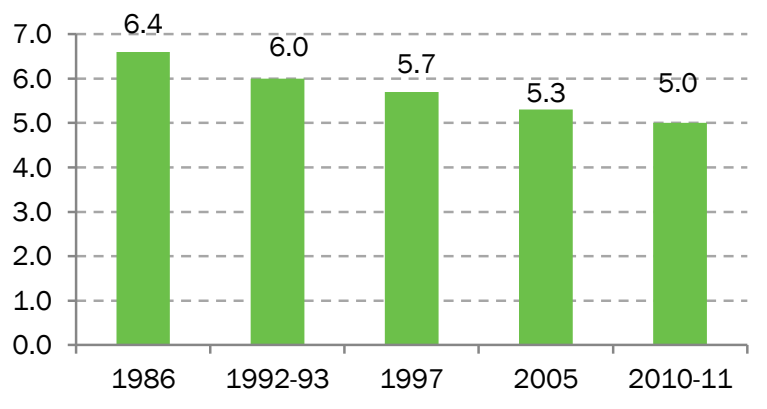

Source: Senegal DHS-MICS 2010-11. Key findings
The population in Senegal is unevenly distributed geographically, with a large concentration in the West (where Dakar, the Capital City, is located) and Centre, while the East and the North are sparsely populated. Approximately $23 \%$ of the Senegalese population lives in the Dakar region in an area representing $0.3 \%$ of the country while $5 \%$ live in the country's largest region, Tambacounda. More than 55\% of the Senegalese population lives in rural areas, but the urban population continues to grow. In 2002 the national urbanization level was $45 \%$. 


\section{CHILDBEARING AND CONTRACEPTIVE BEHAVIOR}

The TFR in Senegal is high and close to the desired family size expressed by both women and men. According to the 2010-2011 DHS, married women desire an average family size of 5.3 children while married men desire even more (around 8 children). As is the case in many sub-Saharan countries, the desire for large families in Senegal comes from cultural beliefs that children bring life into the household and that they are an investment. These considerations have direct repercussions on early entry into marriage and childbearing. The 2010-2011 DHS revealed that, despite an increase of the median age at first birth to 21 , $16 \%$ of female respondents aged 15-19 were
FIGURE 2: TEENAGE CHILDBEARING BY EDUCATION (\%)

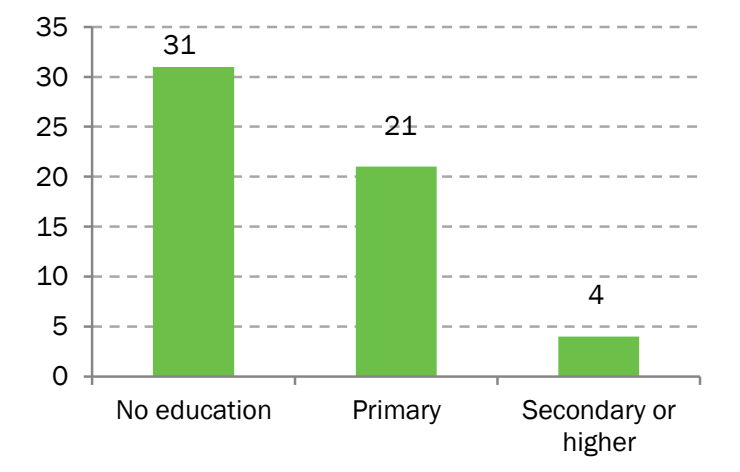

Source: Senegal DHS-MICS 2010-11. Key findings

already mothers, and 3\% were pregnant with their first child. Important differences by socioeconomic categories were also observed. The percentage of teenage childbearing was respectively $31 \%, 21 \%$ and $4 \%$ for adolescents with no education, primary education, and secondary or higher education (Figure 2). Teenage childbearing is even more evident in rural areas (25\% compared to $12 \%$ in urban areas).

Beyond cultural beliefs explaining the desire for large family, the high rate of fertility is related to the low use of modern contraceptive methods. According to the $2010-2011$ DHS, only $12 \%$ of married women have used modern contraceptive methods. The current methods used by married women are illustrated in Figure 3. The most commonly used are injectables (5\%) and pills (4\%).

FIGURE 3: CURRENT MODERN CONTRACEPTIVE METHODS USE BY MARRIED WOMEN (\%)

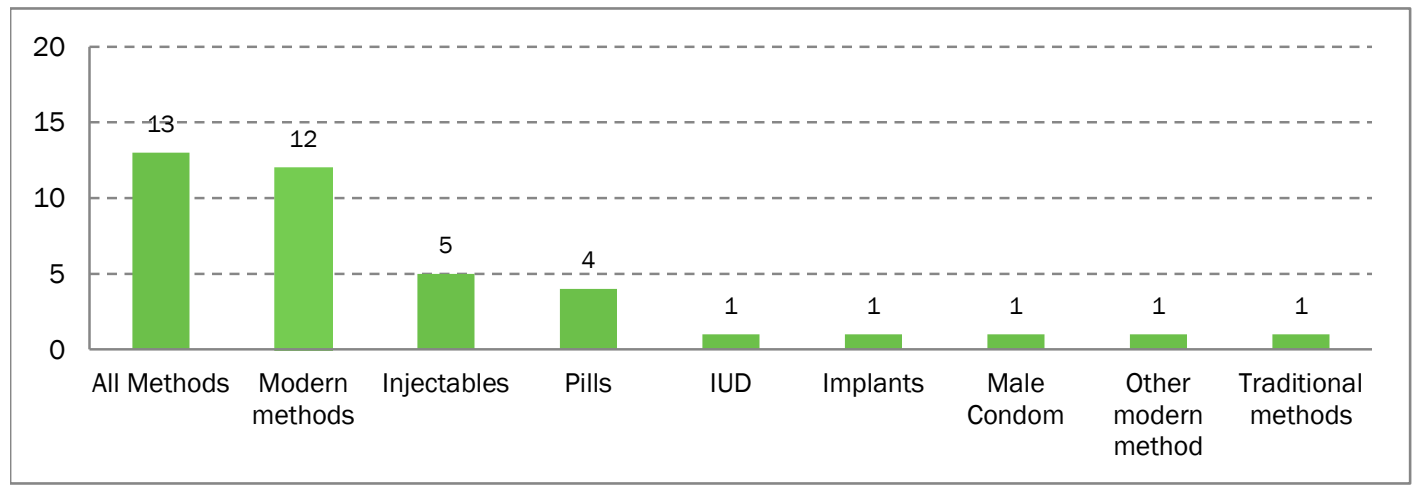

Source: Senegal DHS-MICS 2010-11. Key findings 
Differences in use of modern contraception are noted between socio-economic categories. As Table 2 indicates there is a gap by urban/rural residence with $20 \%$ in urban areas compared $7 \%$ in rural areas. Education displays disparities as well: $26 \%$ of women with secondary education or higher reported use compared to $21 \%$ of women with primary education and $8 \%$ of those with no formal education. Similarly, use of modern methods increased with economic quintile, with $23 \%$ of women in the wealthiest quintile using a modern contraception compared to $4 \%$ in the poorest quintile.

Table 2: Women's use of modern contraceptive methods by socio-economic status

\begin{tabular}{|l|l|}
\hline Socio-economic status & \multicolumn{2}{l|}{} \\
\hline Residence & 20.2 \\
\hline Urban & 6.5 \\
\hline Rural & \multicolumn{2}{l|}{} \\
\hline Education & 8 \\
\hline No formal education & 21 \\
\hline Primary Education & 26 \\
\hline Secondary education or higher & \multicolumn{2}{l|}{} \\
\hline Economic quintile & 4.4 \\
\hline Poorest & 6.8 \\
\hline Second quintile & 12.0 \\
\hline Middle quintile & 15.2 \\
\hline Fourth quintile & 22.9 \\
\hline Richest quintile & \\
\hline
\end{tabular}

Source: Senegal DHS-2010-2011. ANSD.2012.

The dual challenges associated with early marriage and lack of education are that women often lack the ability to negotiate safe sex or use of a modern birth control method. This also decreases the chances that a woman will be able to practice postpartum family planning in order to safely space her pregnancies.

According to the 2010-2011 DHS, approximately 29\% of married women age 15 to 49 had an unmet need for family planning services, with $8 \%$ for limiting their births and $22 \%$ for spacing. The total demand for family planning, including unmet and met needs, was approximately $43 \%$, disaggregated into $31 \%$ demand for spacing and $12 \%$ demand for limiting births (ANSD and ICF-MICS, Demographic and Health Survey, 2012). The magnitude of unmet need is even higher for postpartum women. According to the 2010-2011 DHS, $60 \%$ of women who had a birth in the 2 years prior to the survey reported an unmet need for family planning (Senegal Country profile, STEP UP, 2014). Among postpartum women, $60 \%$ who were breastfeeding reported an unmet need compared to $40 \%$ for those who were not breastfeeding.

Duration of breastfeeding has also increased in Senegal from 17 months in 1986 to a median of 20 months in 2005 and 21 months in 2010-2011 (Senegal country profile, STEP UP, 2013). In 2010-2011, the median birth interval in Senegal was 34 months with 18\% of babies being born within an interval of less than two years after a previous birth (Senegal country profile, STEP UP, 2013). 


\section{Distribution of facilities and human resources for health}

In Senegal, the provision of reproductive health services in the public sector is organized into four levels:

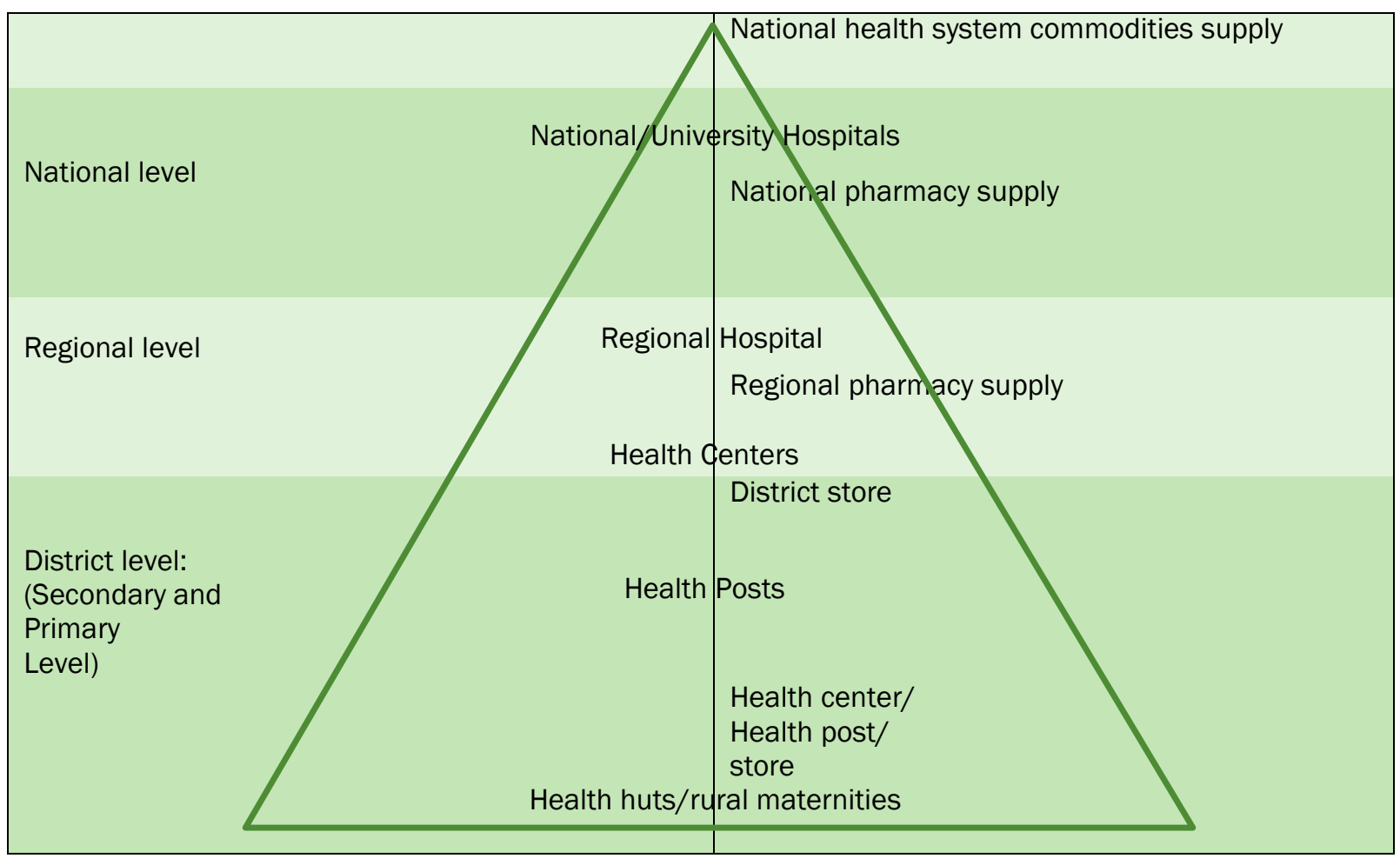

- National level: At the top of the pyramid are the national referral hospitals with a range of specialty services (general medicine, surgery and other specialized care) offered by various cadres of providers (physicians, midwives, nurses, and other lower-level providers). The entire FP method mix is available, including tubal ligation and vasectomy.

- Regional level: At the tertiary level are the regional hospitals which provide referrals to health centers. A range of specialties are offered by various cadres of providers at national hospitals.

- Secondary level: At the secondary level are the health centers that serve as referral centers for health posts. Basic health care (antenatal care, delivery, postnatal care, vaccination, FP) and some specialty services are available but they are limited. Health centers are under the responsibility of a chief physician. A range of providers (physicians, midwives, nurses) are available in these structures.

- Primary level: At this level, there exists two types of facilities: (1) Health posts that are under the responsibility of a nurse or nurse assistant. Primary health care (antenatal care, delivery, postnatal care, vaccination, FP) are offered; and (2) Health huts, which are under the supervision of the health posts, are managed by Community Health Workers (CHWs), usually a matron. At health huts level, matrons perform deliveries and offer various FP services. They are also trained to administer injectables. 
Health centers, posts and huts are under the responsibility of a district management team led by a physician with a public health background.

The private sector and NGO sector contribute to the efforts of the public sector in the provision of reproductive health services. As stated in Article 17 of the Senegalese

Constitution, "the State and public authorities have the social duty to ensure physical, moral and mental health of the family". Through two strategic policy documents, the Declaration of Population Policy (DPP) and the National Health Development Plan (PNDS, 2009-2015), the government initiated measures to promote decentralization in the health sector and to ensure equity in access of health services to the entire population, regardless of their socioeconomic status.

Despite these commitments, a health map conducted in 2011 by the Ministry of Health (MoH) revealed unequal distribution of health facilities and health workforce between regions and between and urban and rural areas. Important gaps were noted vis-a-vis norms set by health authorities.

\section{DISTRIBUTION OF HEALTH FACILITIES}

An analysis of the distribution of health facilities reveals differences vis-a-vis national and WHO norms, particularly with regard to health centers and hospitals. There was 1 health post for 9,604 inhabitants. Although this ratio is close to the WHO norm (one health post for 10,000 inhabitants), there is a gap compared to the PNDS norm of 1 health post for 7,714 inhabitants. In the last decade, considerable efforts have been undertaken by the public authorities to improve access to this category of Service Delivery Points (SDP); however, the coverage of health posts remains low.

The 2011 health map indicated that the number of functional health posts was 1,257, indicating a gap of 320 health posts compared to estimated needs. As for health centers, the 2011 health map indicated that 126 centers were needed, but only 97 were tallied, indicating a gap of 29 centers. The number of inhabitants per health center was 155,515 whereas the norm set by the Ministry of Health (PNDS) was 116,519 inhabitants per health center, and that of the WHO was 50,000 inhabitants per health center. The health map tallied 34 hospitals, a ratio of 480,000 inhabitants per hospital. In comparison, the WHO norm is 150,000 inhabitants per hospital. Senegal needs to build 10 new hospitals to reach theses norms.

Unequal distribution of health facilities was observed between regions and between urban and rural areas. The majority of the facilities were concentrated in the western half of the country. Specifically, half of the hospitals are concentrated in the Dakar and Thies regions. In addition to the gap in the availability of health infrastructures, constraints such as lack of adequate roads, means of transportation and topographical obstacles limit access to health facilities. This is particularly exacerbated in rural areas and in remote regions such as Tambacounda, Kedougou and Matam where walking and horse cart are the most common means of transportation to health facilities. 


\section{HUMAN RESOURCES AVAILABILITY}

The categories of skilled health professionals acknowledged in the Senegal health systems are in hierarchical order: physicians, midwives, nurses and assistant-nurses. Analysis of these human resources reveals inadequate availability and unequal distribution between regions.

In 2011, Senegal counted 1,803 physicians, yielding a ratio of 29,000 inhabitants per physician. It was estimated that 413 additional physicians were needed to reach PNDS norms. The majority of this category of health workers is based in the Dakar $(71 \%)$ and Thies (8\%) regions, creating large disparities between regions. Thus, while the ratio of inhabitants to physicians in the Dakar region was 2,305:1; it was 88,540:1 and 63,637:1 in the Sedhiou and Kaffrine regions, respectively. The same holds true in the private sector, where $23 \%$ of physicians are mainly in the urban settings. High levels of poverty and financial barriers to seeking care from physicians, especially for specialty services such as gynecology and pediatrics, remain major challenges.

In 2011, 1,103 midwives were registered in Senegal. Similar to physicians, a large proportion (37\%) were concentrated in Dakar region, contributing to wide disparities between Dakar and the rest of the country. While there was one midwife for 1,475 women of reproductive age in Dakar, the ratio was 1 for 7,318 in Kaffrine, 1 for 5,202 in Matam and 1 for 4,467 in Tambacounda region. 805 additional midwives must be recruited to reach the PNDS norms.

A total of 4,102 nurses and assistant-nurses were registered in Senegal in 2011, with 38\% living in the Dakar region. The national ratio was 1 nurse for 3,952 inhabitants, with wide regional disparities. For example, the ratio was 1 for 1,680 in Dakar compared to 1 for 66,303 in Diourbel region, 1 for 5,465 in Sedhiou region, and 1 for 4,133 in Kolda region. The need for new recruitment was estimated at 1,950.

In addition to these skilled workers, various cadres of CHWs exist in Senegal, including:

- Matrons: Matrons provide FP services in health huts. They perform deliveries, distribution of essential medicines (oxytocin, misoprostol, oral rehydration solutions (ORS), iron, zinc combined with artemisinin-based therapy, Vitamin A), and distribution in pilot sites of some family planning methods including standard days methods, male and female condoms, pills and injectables.

- Community Health Agents (ASC): Working at the health hut level, ASCs deliver primary health care, vaccination, and FP services (in pilot sites) including standard days methods, male and female condoms, pills and injectables.

- Relais: Based at community level, Relais provide general information on FP and perform home visits.

- Badienu Gox: Badienu Gox are key opinion leaders selected by their community. They promote positive behaviors, especially FP, and provide referrals and advocacy activities targeting male community leaders.

The low availability of health facilities and shortage of skilled human resources constitute a major limitation to ensuring continuity and quality of care throughout the health system. Furthermore, the unequal distribution of these resources exacerbates issues of access to services. This situation calls for an implementation of alternative strategies to improve access to health services. Task sharing could offer a valuable alternative to contribute to addressing these barriers by relying more on all available human resources. 


\section{Considerations for introducing contraceptive vaginal rings}

\section{AT THE HEALTH SYSTEM LEVEL}

In November 2012 the Government of Senegal launched its National Family Planning Action Plan for the period 2012-2015. The objective of this ambitious plan is to increase contraceptive prevalence rate (CPR) from $12 \%$ to $27 \%$ by 2015 , and to $45 \%$ in 2020 (Ministère de la Santé et de l'Action Sociale, Direction de la Santé de la Reproduction, 2012). To achieve its 2015 goal, the plan aspires to recruit 350,000 new contraceptive users. Six broad domains for strategic interventions are defined: (1) wide-reaching national communication plan including research and targeted communication campaigns; (2) targeted advocacy to raise awareness of and support for family planning on local and national agendas and to increase resources to address family planning needs; (3) commodity security for contraceptive products, particularly through the implementation of the "Informed Push Model"; (4) improvement of services offered by the public health sector, particularly long-term methods, by securing material resources and reinforcing competencies of health agents; (5) reinforcement of services offered by the private sector, notably by increasing market choice and availability of products; and (6) expansion of community-level distribution of products in order to reach hard-to-reach communities (Ministère de la Santé et de l'Action Sociale, Direction de la Santé de la Reproduction, 2012).

To further contribute to repositioning the national FP program, the government encourages the expansion of the method mix currently available to couples to achieve their reproductive health goals. Expanding choice is also expected to attract non-users. With this goal in mind, the $\mathrm{MoH}$ has encouraged, in recent years, several initiatives for new product introductions or acceptability studies, including the Depo Provera IM (at community level), Depo-subQ Provera (Sayana Press) (by matrons), the Implanon implant, and the PCVR.

To address the lack of human resources, particularly in rural settings, the national FP program emphasizes an increased role for Community Health Workers (CHW) in the distribution of FP products. Moreover, the government has undertaken a policy of decentralization of health services so that services are accessible geographically and financially and are socio-culturally and religiously acceptable. The policy also ensures regional-level buy-in by: (1) strengthening human resources and providers' training; (2) transferring technical and managerial skills; and (3) increasing stakeholders' accountability at all levels, including the community level. As a result, a dense network of $\mathrm{CHWs}$ is contributing to reinforcing the provision of family planning services. PCVR is an easy-to-use, user-initiated method that can be conveniently provided at all levels of the health system with limited training of providers. 


\section{AT THE INDIVIDUAL LEVEL}

The 2012-2013 Continuous DHS reported a CPR of modern contraception of $16 \%$ and an unmet need of nearly 30\% (Continuous DHS, 2013). Owing to lack of infrastructure and of skilled human resources, access to health services remains a challenge and health care utilization remains low. As a user-initiated method, the PCVR offers a good option to address these challenges. Women do not need to rely to skilled health workers for obtaining the method. Moreover, they might not need to travel long distances to obtain it since it has the potential for distribution by front line health care providers or community-based workers at the lowest level of the health system.

\section{NEED FOR TASK SHARING}

Since the 1990s, national authorities have been engaged in decentralization of the health program. This decision was motivated by the need to ensure equity in access to health services for each citizen as stated by the Constitution. This policy is aimed mainly at addressing the lack of skilled human resources, particularly at the primary level of the health system. The policy is based on revitalizing and staffing health huts; and training $\mathrm{CHWs}$ to perform basic primary care (delivery, vaccination) and educational activities for health prevention (information and education). The growing shortage of skilled providers and unavailability in rural areas led the Government to initiate task sharing and task shifting in the first national FP program, with the goal of ensuring wide access to basic primary health care services by underserved communities. CHWs, especially matrons, were trained to take on new tasks. For family planning, selected $\mathrm{CHWs}$ were first trained to perform initial counseling for new clients. These CHWs were based in health facilities and worked under the direct supervision of a skilled provider, usually a midwife. This initiative was motivated by the need to free midwives from educational activities, thus allowing them to perform more clinical tasks such as method-specific counseling and service delivery.

In the mid-2000, the MoH began to support FP method provision by matrons at health huts. The matrons were trained to resupply pills users. After this positive experience, matrons were trained to perform initial offering of pills, then injectables, in their communities. Thereafter, the $\mathrm{MoH}$ launched the Badienu Gox initiative. These community health workers were identified as key opinion leaders in charge of promoting $\mathrm{RH}$ in their communities and referring women to health posts for of $\mathrm{RH}$ services (ANC, delivery, vaccination, malaria treatment, FP).

All these initiatives demonstrate the commitment of national authorities to ensure equal access to health services and to address barriers limiting access to health services. Recently, the $\mathrm{MoH}$ engaged developing a strategic plan to consolidate and promote community health program. Task shifting is front and center in this plan.

\section{TASK SHARING INITIATIVES}

To address the high levels of maternal and neonatal mortality observed in the country, the $\mathrm{MoH}$, through the implementation of its reproductive health program, experimented with various approaches to task sharing. The $\mathrm{MoH}$ began by assigning educational tasks to $\mathrm{CHWs}$ 
who were trained to provide health information in their communities. These CHWs were also assigned to make referrals to health posts. Positive lessons from this experience encouraged the $\mathrm{MoH}$ to add other tasks to $\mathrm{CHWs}$, such as distribution of essential medicines including vitamin A, iron, oxytocin, misoprostol for postpartum hemorrhage prevention, and ORS, to improve access to essential maternal and newborn care.

In the 1990s, the national FP program initiated a training program for CHWs assigned at the level of the clinic. Focus was on education and FP counseling to clients, a task formerly performed by midwives who became available to perform more clinical tasks. At community level, relais were trained to perform educational activities to raise awareness about FP and to refer women to skilled providers for appropriate services. The relais also performed mobilization activities, condom distribution and other tasks such as home visits to FP clients and referrals to health posts. In addition, they were involved with data collection tools for the Health Information System (HIS).

In 1998, with funding from the African Development Bank (BAD) and in collaboration with the Gynecology and Obstetrics Clinic of the University of Dakar, the MoH initiated a training program in emergency obstetric surgery for district teams (including an anesthetist, a general practitioner and a surgical assistant). This program was experimented in Tambacounda, Kolda, Fatick and Kaolack regions. It consistently demonstrated improvement in access to emergency care in all three regions. Another task shifting initiative was to introduce Obstetrical and Neonatal Care at lower levels of the health pyramid by training nurses and midwives to manage basic maternal and neonatal care such as Active Management of the Third Stage of Labor (AMSTL), essential newborn care, echography and Post Abortion Care (PAC). These tasks were previously performed by physicians.

Positive lessons from these experiences showed that, when trained adequately, CHWs were able to deliver effective and safe services in their communities and to raise awareness about $\mathrm{RH}$ issues. Results from these pilots motivated FP program managers to integrate task shifting approaches in their interventions.

\section{CURRENT TASK SHARING POLICY IN SENEGAL}

For decades, the national authorities have engaged in a policy to decentralize health services through the implementation of successive National Health Development Plans (PNDS). The PNDS aims to involve and hold local authorities and actors accountable in the implementation of health policy as part of a decentralized governance system. The PNDS also encourages community-based distribution of reproductive health products and services to ensure local service delivery. Various cadres of $\mathrm{CHWs}$ are involved. These strategic orientations confirm the commitment of national authorities to support task sharing initiatives, and although task sharing is not explicitly mentioned as a national priority in policy documents, national authorities continue to support this strategy that contributes to improving access to health services. 
Selected task sharing and/or task shifting experiences conducted in Senegal are reviewed below:

\section{Initial FP counseling by community health workers}

In the 1990s the MoH initiated training of matrons in FP counseling. This initiative aimed to free midwives to allow them to focus on more clinical task. The effort showed that trained $\mathrm{CHWs}$ can competently conduct general FP counseling, allowing midwives to focus on method-specific counseling and other clinical services. Positive results from this experience encouraged the $\mathrm{MoH}$ to scale up this initiative throughout the system. Currently initial counseling and women's education on $\mathrm{RH}$ matters are performed by trained $\mathrm{CHW}$ under the supervision of midwives or nurses. These FP counselors are now available in the majority of health facilities.

\section{Initial offering of contraceptive pills by matrons}

In 2008, with funding from USAID, the $\mathrm{MoH}$ introduced a pilot initiative whereby matrons were allowed to provide contraceptive pills. The pilot intervention, led by Childfund, covered 8 regions (Fatick, Kaffrine, Kaolack, Kolda, Louga, Sedhiou, Thies and Ziguinchor). A total of 206 matrons were trained in the safe delivery of first offering of pills. During implementation, no serious adverse events were noted, and matrons were able to adequately address sideeffects reported by users. Most clients expressed satisfaction with services received. The evaluation revealed that, when matrons are well trained, they can perform safe and proper administration of pills at community level. Data from the midterm evaluation showed that the number of women using pills increased from 502 in 2008 to 5,141 in 2009. Between 2008 and 2009, the number of users re-supplied with pills increased from 127 to 3,187; and the number of drop outs decreased from 180 to 153 during the same period. Matrons adhered to counseling procedures and were able to fill data collection forms properly. Based on the results of this pilot experience, the intervention was deemed a best practice and the $\mathrm{MoH}$ began its scaling up across the country.

\section{Long-acting methods offered by nurses}

From 2006-2011, with funding from USAID, IntraHealth implemented a task shifting initiative to have head nurses provide long-acting methods at health post level, namely implants and IUD. Previously, these methods were only available at referral centers, i.e. health centers and hospitals, and administered by physicians and midwives. Until then, based on Norms and Protocols for FP services delivery, head nurses were not allowed to offer these methods, and these were not included in their training curriculum. The intervention covered more than 600 health posts. Trained head nurses received IUD and implant kits to allow them consolidate their skills. The evaluation of this initiative, published in 2011 by IntraHealth titled "Déléguer des tâches pour améliorer l'accès à la planification familiale," indicated that trained head nurses can safely offer these long-acting methods. The initiative contributed to expanding FP choice for women living in remote areas and helped to reinforce access to FP services. Head nurses demonstrated great motivation in performing this task. Long-acting methods are now available at health post level in 12 regions out of 14 (excluding Matam and Tambacounda) with head nurses being the main providers. 
DMPA-IM offered by matrons and community health agents

After the successful experience of community-based provision of pills, national authorities initiated a pilot for the provision of injectables by matrons at the community level (health huts). The initiative led by Childfund involved other partners including FHI360 and CEFOREP. It aimed at assessing the feasibility and acceptability of including DMPA-IM in the range of FP methods offered by matrons and community health agents. From August 2012 to March 2013, the intervention covered 36 health huts in three districts in three regions (Joal in Thies region; Dioffior in Fatick region and Nioro in Kaolack region). Results from the evaluation showed that matrons and community health agents developed the necessary skills to provide DMPA-IM correctly. The provision of DMPA-IM by matrons and community health agents contributed to the diversification of methods offered at health huts level. Matrons served around 1,078 clients, including 670 who chose injectables. Clients as well as other health personnel appreciated this task sharing experience. Ninety-nine percent of clients appreciated the expanded access to FP methods and reported that they intended to get their next injectable at health huts levels.

\section{Acceptability of Depo-subQ Provera 104 in Uniject (Sayana ${ }^{\circledR}$ Press)}

In 2012, the MoH supported efforts for the introduction of the Depo-subQ Provera 104 TM in Uniject into Senegal (Ministère de la Santé, PATH, and FHI360: Acceptability of Depo SubQ in Uniject in Senegal. July 2013). This was a collaborative project between PATH, FHI360 and CEFOREP. Depot medroxyprogesterone acetate (Depo-Provera ${ }^{\circledR}$ or DMPA) is a widely used injectable contraceptive that was typically delivered through intramuscular (IM) injection. Pfizer developed a subcutaneous formulation called DMPA - Depo-subQ provera 104 (abbreviated as Depo-subQ) - in a prefilled glass syringe under the trade name Sayana ${ }^{\circledR}$. Depo-subQ can also be used in the Uniject ${ }^{\mathrm{TM}}$ - an auto-dispensable injection system - which is expected to be a more appropriate way to deliver DMPA in low-resource settings. Working in three districts of the Thies region (Mbour, Thies, and Tivaouane), the study assessed the acceptability of Depo-subQ in Uniject, commercially known as Sayana ${ }^{\circledR}$ Press, among FP providers and clients. Twelve health facilities were selected that were already offering family planning services along with a community-based distribution (CBD) program with matrons providing oral contraceptives and condoms. Findings from the evaluation demonstrated that trained matrons can safely administer Depo-subQ in Uniject. No adverse events were reported. Clients showed interest in the method which confirmed the potential of Depo-subQ in increasing FP access through community-based distribution. They appreciated both the new method and the provision of service by matrons. Following this positive experience, the $\mathrm{MoH}$ in August 2014 signed in an official communication opening the way to a scale up this initiative throughout the country, as stated by the national plan on scaling up best practices. Additional regions such as Dakar, Thies, Fatick and Kaolack will pursue this experience in 2015. 


\section{SUCCESSFUL TASK SHARING ACTIVITIES}

Evaluations of task shifting/sharing experiences in Senegal revealed that, when well trained, CHWs can adequately offer basic primary health care services in the communities where they work. They are able to provide comprehensive health information and services, and can handle health questions and complaints brought up by community members. Moreover, services offered at the community level (health huts) were of acceptable quality and greatly appreciated. A recent evaluation led by USAID (USAID: Lessons learned from the Senegal Community Health program. May 2011) on the initial pills offer confirmed that, when asked about the quality of the greetings at their visit to the health hut, $95 \%$ of the clients expressed complete satisfaction.

Furthermore, education activities led by CHWs increased awareness of family planning, and their presence in the community boosted demand for and use of services. In addition, as expressed by a head nurse, "the presence of CHWs has led to a decrease in caseloads at the health post. Head nurses can focus more on treating serious cases of malaria, diarrhea and respiratory infections."

There are also geographic and financial advantages to the availability of competent services at the level of the health huts. Thus, task shifting contributed to reducing travel distance, time and costs for getting health services. Through their educational activities in the community, CHWs have the opportunity to address cultural barriers limiting utilization of health services by individuals and families.

In addition, providers and local management teams confirmed that CHWs and matrons can systematically respect norms and protocols.

\section{INTEGRATION OF SERVICES}

Based on positive previous experiences of task shifting, this approach is likely to accelerate the uptake of contraceptive vaginal rings as well. Many factors in favor of this expectation include:

- As a woman-initiated method, contraceptive vaginal rings fit well within this approach to service delivery.

- Contraceptive vaginal rings are easy to use, and a strategy for their introduction at community level could build on previous experiences such as of the initial offer of pills by matrons and the use of Sayana Press at the community level.

- Senegal has a dense network of $\mathrm{CHWs}$ that can facilitate this initiative at community level.

- National authorities have undertaken an ambitious program for repositioning FP. Based on the experience of the acceptability study of the PCVR, they are eager to integrate the ring into the national family planning program. 


\section{Conclusion}

Positive task sharing and task shifting initiatives undertaken in Senegal suggest that there is great potential for distribution of contraceptive vaginal rings by lower-level health workers. With the implementation of the 2012-2015 National FP actions plan, the MoH expressed a commitment to sustaining the repositioning of the FP program. Task sharing of FP services that gives a more prominent role to community actors, and improved access to services constitute key strategies of the plan. Recent task shifting initiatives demonstrated that CHWs could provide good quality services in their communities. These experiences contributed to increased access and uptake of FP services.

The $\mathrm{MoH}$ adopted a plan for scaling up best practices nationally. Relying on the existing network of community health workers is a good strategy for addressing the shortage of skilled health workers, particularly in rural and remote areas. Task sharing offers good perspectives for the provision of the PCVR and other vaginal rings. Trained CHWs could also contribute to an increased demand for contraception and reduced barriers to access. The $\mathrm{MoH}$ engaged in developing a strategic plan for a community health program. However, it will be important to learn lessons from previous initiatives and anticipate some of the challenges they faced. Among these challenges, the following need to be addressed:

\section{SUSTAINABILITY}

Task shifting initiatives that involve CHWs need to plan for sustainability from the onset. Since the majority of CHWs are unpaid volunteers, in the absence of incentive, economic or noneconomic, they tend to stop providing services. Furthermore, they may act as barriers to potential users who may be seeking services. That can be a source of demotivation. Furthermore, all the pilot initiatives were funded by external partners. It is crucial to mobilize local resources for ensuring sustainability in implementation.

\section{ENSURING SUPPLIES}

The availability of commodities remains a challenge at the facility level. Previous initiatives faced regular shortages of products and data collection forms at health posts and health huts, which can be detrimental to adequate implementation of any task sharing initiative.

\section{DECENTRALIZED SYSTEMS}

New task sharing initiatives must understand the decentralized system and identify responsibilities and authorities of key actors at various levels. Furthermore, supervision of $\mathrm{CHWs}$ by health posts remains a challenge since the workload of nurses does not allow them to conduct regular monitor as set out by the $\mathrm{MoH}$. The lack of supervision could have negative impact on CHWs' performance.

\section{HEALTH SYSTEM RESISTANCE}

Since task sharing will lead to changes in the roles and responsibilities of the diverse health cadres, existing hierarchical structures might need to be transformed. It will be important to carefully manage changing dynamics brought about by the sharing of power and authority. 


\section{References}

1. Agence Nationale de la Statistique et de la Démographie : enquête démographique et de santé à indicateurs multiples. Sénégal. Rapport final (EDS-MICS) 2010-2011. Dakar.

2. Agence Nationale de la Statistique et de la Démographie : enquête démographique et de santé continue. 2012-2013.

3. Agence Nationale de la Statistique et de la Démographie : enquête continue sur la prestation des services de soins de santé au Sénégal. Rapport 1ère année. 2014. Dakar

4. CEFOREP, FHI, Ministère de la Santé et de l'Action sociale : Etude de faisabilité et d'acceptabilité de l'administration du Depo par voie intramusculaire par les matrones et Agents de santé communautaire des cases de santé. Avril 2013.

5. IntraHealth : Déléguer des tâches pour améliorer l'accès à la planification familiale. 2011. Fact sheet.

6. Ministère de la Santé et de l'Action sociale : carte sanitaire du Sénégal. 2011. Juillet 2012. Dakar

7. Ministère de la Santé et de l'Action sociale : Plan National de Développement sanitaire et social. 2009-2011. Dakar

8. Ministère de la santé : Plan National d'Action pour la Planification Familiale. 2012

9. Ministère de la santé, USAID : Documentation du processus de l'offre initiale de la pilule par les matrones des cases de santé. Avril 2010

10. Ministère de la santé : Etude de faisabilité et d'acceptabilité de l'administration du Depo par voie intramusculaire par les matrones et ASC des cases de santé. Avril 2013

11.PATH, Ministère de la Santé, FHI360 : Acceptability of Depo SubQ in Uniject in Senegal. July 2013.

12. Population Council: Delivering a family of contraceptive vaginal ring. Technical proposal. NY. May 2013

13. USAID, FHI 360, CEFOREP and PATH: acceptability of Depo-subQ in Uniject in Senegal. Final technical report. July 2013.

14.STEP UP: Senegal Country profile. 2014

15.STEP UP: insights into unmet need in Senegal. March 2013

16.USAID: Lessons learned from the Senegal Community Health program. May 2011.

17. WHO: Recommendations optimizing health worker roles to improve access to key maternal and newborn health interventions through task shifting. Geneva, 2013) 

Population Council Sacré Cœur 3. Lot 85. BP 21027 